\title{
Experimental Study and Prediction Model of the Flexural Strength of concrete Containing Fly Ash and Ground Granulated Blast-Furnace Slag
}

\author{
Hua Zhang $\mathbb{D}^{\text {, }}$, Qing-Fu Li $\mathbb{D}^{\text {D }}$, Hua-De Zhou, and Zong-Ming Song \\ School of Water Conservancy Engineering, Zhengzhou University, Zhengzhou 450001, China \\ Correspondence should be addressed to Qing-Fu Li; lqflch@zzu.edu.cn
}

Received 7 May 2021; Revised 1 October 2021; Accepted 12 October 2021; Published 24 November 2021

Academic Editor: Tomas Hanak

Copyright (c) 2021 Hua Zhang et al. This is an open access article distributed under the Creative Commons Attribution License, which permits unrestricted use, distribution, and reproduction in any medium, provided the original work is properly cited.

\begin{abstract}
Orthogonal experiments were performed to study the flexural strength of an eco-friendly concrete containing fly ash (FA) and ground granulated blast-furnace slag (GGBFS). The effects of different test parameters, such as water-binder ratio (W/B), FA content, GGBFS content, sand ratio, gravel gradation, and curing time, on the flexural strength of the concrete were analyzed. The significance level of each influencing factor and the optimal mixing proportion of the concrete were determined by range analysis and hierarchy analysis. It was found that the W/B ratio had the greatest influence on the flexural strength of the concrete. The flexural strength of the concrete decreased gradually with the increase of W/B. The GGBFS content and the sand ratio had a greater influence in the early stage of concrete curing. The middle and later stages of concrete curing were mainly affected by gravel gradation and the FA content. A flexural strength prediction model of the concrete was developed based on a backpropagation neural network (BPNN) and a support vector machine (SVM) model. It was noticed that the BPNN and SVM models both had higher accuracy than the empirical equation, and the BPNN model was more accurate than the SVM model.
\end{abstract}

\section{Introduction}

Concrete is one of the most widely used building materials due to its good quality and low price [1]. Concrete structures are mainly subjected to bending rather than axial tension. However, the flexural properties of concrete are poor, and cracks easily appear under tensile stress conditions. Therefore, it is of great significance to improve the flexural strength of concrete [2]. Supplementary cementitious materials, such as fly ash, ground granulated blast-furnace slag, and silica powder, are generally used to improve the performance of concrete, reduce the waste stock, and lower the construction cost [3].

Fly ash (FA) is a waste discharged after pulverized coal combustion. It has a high storage cost and can cause environmental pollution $[4,5]$. Nili $\mathrm{M}$ et al. [6] studied the influences of FA on concretes of different ages and noticed that FA greatly enhanced the concrete strength in the later stage of curing. Golewski [7] studied the compressive strength and fracture toughness of concrete with FA contents of $20 \%$ and $30 \%$. It was reported that the compressive strength and fracture toughness of concrete were significantly improved when the FA replacement ratio was $20 \%$. When the FA replacement ratio was 30\%, the improvement of material properties did not appear until six months after curing. Golewski [8] found that the optimal FA content to improve the fracture toughness of concrete was $17 \%$ (by weight). The fracture toughness of concrete began to decrease when the FA content exceeded $23 \%$ of the total cementitious material. Atis [9] reported that the flexural strength of 70\% FA-replaced concrete after 7, 28, 90, and 365 days was reduced by $46.83 \%, 24.71 \%, 26.2 \%$, and $35.16 \%$, respectively, as compared to that of $50 \%$ FA-replaced concrete.

Ground granulated blast-furnace slag (GGBFS) is a byproduct of iron smelting [10]. Extensive research has been performed on GGBFS-substituted concrete. Hogan et al. [11] conducted a comparative study on ordinary concrete and 
GGBFS-substituted concrete with $40 \%$ and $60 \%$ replacement ratios. The compressive strength of the GGBFS-substituted concrete was found to be lower than that of the ordinary concrete in the first three days. However, the compressive strength of the GGBFS-substituted concrete increased at a higher rate than that of the normal concrete after three days, especially when the GGBFS replacement ratio was $40 \%$. The GGBFS-substituted concrete had the same or higher flexural strength than the ordinary concrete after seven days. Sivasundaram et al. [12] studied the variation of the flexural strength of GGBFS-substituted concrete with 50\%-75\% replacement ratios. The flexural strength of the GGBFSsubstituted concrete after 14 days was higher than that of common concretes. However, some studies have reported opposite results. For example, Khatib et al. [13] studied the effects of different GGBFS replacement ratios $(0 \%, 40 \%$, $60 \%$, and $80 \%$ ) on the flexural strength of concrete. It was found that the concrete flexural strength with a GGBFS replacement ratio of $60 \%$ was significantly higher than that of the control group and decreased slightly when the replacement ratio was $40 \%$. A significant decrease in flexural strength was noticed when the replacement ratio was $80 \%$. Bharatkumar et al. [14] reported a reduction in the flexural strength of GGBFS-substituted concrete. When the total amount of cementitious material was $472 \mathrm{~kg} / \mathrm{m}^{3}$ and the water-cement ratio was 0.36 , the addition of $50 \%$ of GGBFS decreased the 56 -day bending strength by $7.2 \%$. When the total amount of cementitious material was $430 \mathrm{~kg} / \mathrm{m}^{3}$ and the water-cement ratio was 0.4 , this drop reached $11.29 \%$. Nazari and Riahi [15-18] found that the 7-day flexural strength of concrete was reduced by $24.32 \%$ and $32.43 \%$, respectively, when cement was partially replaced with $45 \%$ and $60 \%$ of GGBFS. On the contrary, the addition of GGBFS increased the 28-day and 90-day flexural strengths of the concrete.

Machine learning methods are also widely used in the field of concrete strength prediction. Zheng et al. [19] developed a stable concrete compressive strength development over time (CCSDOT) model by combining conventional methods with artificial intelligence. Chithra et al. [20] used multiple regression analysis and an artificial neural network to predict the compressive strength of concrete containing silica and copper slag and reported that the artificial neural network model had higher accuracy and relevance. Chou et al. [21] predicted the compressive strength of a highperformance concrete by a support vector machine (SVM) model based on mean absolute percentage error (MAPE). Omran et al. [22] predicted the compressive strength of concrete containing lightweight aggregates and Portland limestone cement by seven different models-three advanced predictive models, four regression tree models, and two ensemble methods. The SVM model was based on sequential minimum optimization, and test results revealed that all models acquired acceptable prediction performance, except for decision stump. Thi Mai et al. [23] developed a random forest model to predict the compressive strength of concrete based on artificial neural network (ANN) and adaptive-network-based fuzzy inference system models (ANFIS) and noticed that these two machine learning methods had high accuracy. Palika Chopra et al. [24] used a decision tree (DT) model, a random forest (RF) model, and a neural network to predict the compressive strength of concrete, and the neural network model was found to have higher prediction accuracy.

With the growing environmental pollution problems and the urgent demand for green construction, environment-friendly concretes need to be developed. In the present work, orthogonal experiments were performed to study the flexural strength of an eco-friendly concrete containing FA and GGBFS. The effects of different test parameters, such as water-binder ratio (W/B), FA content, GGBFS content, sand ratio, gravel gradation, and curing time, on the flexural strength of the concrete were analyzed. The significance level of each influencing factor was determined by range analysis and hierarchy analysis. Moreover, a flexural strength prediction model of the concrete was developed based on a backpropagation neural network (BPNN) model and an SVM model, and the prediction accuracies of these two machine learning models and an empirical equation were compared.

\section{Materials and Methods}

2.1. Materials. Water, cement, river sand, gravel, FA, GGBFS, and a water reducer were used as raw materials. Portland cement $42.5 \mathrm{R}$ was used in this research, and its initial and final setting times were 145 and $211 \mathrm{~min}$, respectively. According to the Chinese Building Code GB/T 14684-2011 "Natural River Sand for Construction," natural river sand with a fineness modulus of 2.8 was used as the fine aggregate. According to the Chinese standard GB/T 146852011 "Gravel and Crushed stone for Construction," two types of gravels with different grades were used (maximum particle sizes were $20 \mathrm{~mm}$ (G1) and $40 \mathrm{~mm}$ (G2)). First-grade FA was selected according to the Chinese standard GB/ T1596-2005 "Fly Ash Used in Cement and Concrete." GGBFS with a density of $2.88 \mathrm{~g} / \mathrm{cm}^{3}$ and a specific surface area of $463 \mathrm{~m}^{2} / \mathrm{kg}$ was used. The gradation curves of different mixtures are shown in Figure 1. The chemical compositions of FA and GGBFS are presented in Table 1, and their properties are listed in Table 2.

2.2. Mixing Proportions. The W/B ratio, the contents of FA and GGBFS, the sand ratio (mass ratio of sand to the total mass of aggregates (mass sum of sand and coarse aggregate) [25]), and gravel gradation were considered as the main influencing factors, and each factor had four levels. Therefore, 16 different mixing proportions were determined based on the orthogonal design method. The levels were determined by literatures $[7,8,26-28]$ : $\mathrm{W} / \mathrm{B}$ ratio $=0.35$, $0.375,0.40,0.425$, sand ratio $=33 \%, 35 \%, 37 \%, 39 \%$, FA and GGBFS contents $=5 \%, 10 \%, 15 \%, 20 \%$, gravel gradation with small stones $(5-20 \mathrm{~mm})$ and medium stones $(20-40 \mathrm{~mm})=$ 30\%:70\%, 40\%:60\%, 50\%:50\%, 60\%:40\% (Table 3).

2.3. Test Procedure. Specimens with different mixing proportions were cured for 1 day, 3 days, 7 days, 14 days, 28 


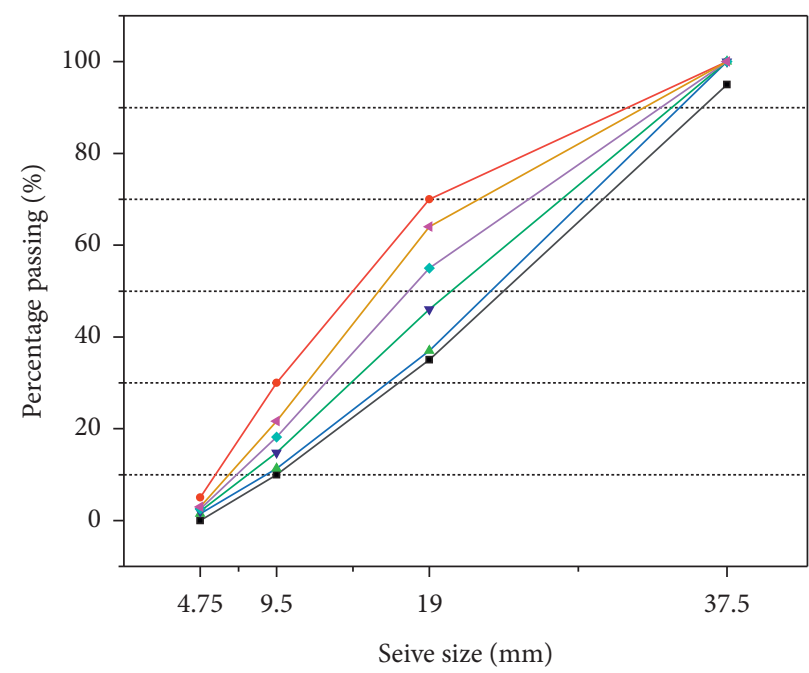

- lower limit of gradation $\rightarrow$ 40:60 gradation
$\rightarrow$ Upper limit of gradation $\rightarrow-50: 50$ gradation
$\simeq$ 30:70 gradation $\multimap 60: 40$ gradation

FIGURE 1: Gradation curves of different mixtures.

TABle 1: Chemical compositions of FA and GGBFS.

\begin{tabular}{lccccccccc}
\hline Constituent (\%) & $\mathrm{SiO}_{2}$ & $\mathrm{Al}_{2} \mathrm{O}_{3}$ & $\mathrm{CaO}$ & $\mathrm{MgO}$ & $\mathrm{SO}_{3}$ & $\mathrm{Fe}_{2} \mathrm{O}_{3}$ & $\mathrm{Na}_{2} \mathrm{O}$ & $\mathrm{K}_{2} \mathrm{O}$ & $\mathrm{H}_{2} \mathrm{O}$ \\
\hline FA & 58 & 30 & 2.8 & 1.5 & 1.22 & 4.3 & 0.00 & 1.36 & 0.5 \\
GGBFS & 33.84 & 13.27 & 40.8 & 6.08 & 0.29 & 0.28 & 0.2 & 0.36 & 0.3 \\
\hline
\end{tabular}

TABLE 2: Main properties of FA and GGBFS.

\begin{tabular}{lccccc}
\hline Properties & Fineness & Water demand ratio (\%) & Loss on ignition (\%) & Density $\left(\mathrm{g} / \mathrm{cm}^{3}\right)$ & Fluidity ratio $(\%)$ \\
\hline FA & 9.22 & 91 & 5.0 & 2.252 & - \\
GGBFS & - & - & 1.236 & 0.88 & 95 \\
\hline
\end{tabular}

TABLE 3: Mix proportions.

\begin{tabular}{|c|c|c|c|c|c|c|c|}
\hline \multirow{2}{*}{ Specimen number } & \multicolumn{7}{|c|}{ Mix proportions $\left(\mathrm{kg} / \mathrm{m}^{3}\right)$} \\
\hline & Water & Binder & FA & GGBFS & Sand & Small gravel & Middle gravel \\
\hline$S 1$ & 135 & 386 & 19.3 & 19.3 & 620 & 378 & 881 \\
\hline$S 2$ & 135 & 386 & 38.6 & 38.6 & 658 & 488 & 733 \\
\hline S3 & 135 & 386 & 57.9 & 57.9 & 695 & 592 & 592 \\
\hline$S 4$ & 135 & 386 & 77.2 & 77.2 & 733 & 688 & 458 \\
\hline S5 & 135 & 360 & 18 & 36 & 629 & 766 & 510 \\
\hline S6 & 135 & 360 & 36 & 18 & 667 & 619 & 619 \\
\hline S7 & 135 & 360 & 48 & 72 & 705 & 480 & 720 \\
\hline S8 & 135 & 360 & 72 & 48 & 743 & 349 & 813 \\
\hline$S 9$ & 135 & 338 & 16.9 & 50.7 & 636 & 516 & 775 \\
\hline$S 10$ & 135 & 338 & 33.8 & 16.9 & 674 & 376 & 877 \\
\hline$S 11$ & 135 & 338 & 50.7 & 67.6 & 713 & 728 & 486 \\
\hline$S 12$ & 135 & 338 & 67.6 & 33.8 & 752 & 588 & 588 \\
\hline$S 13$ & 135 & 318 & 15.9 & 63.6 & 643 & 652 & 652 \\
\hline S14 & 135 & 318 & 31.8 & 44.7 & 681 & 760 & 506 \\
\hline$S 15$ & 135 & 318 & 44.7 & 31.8 & 720 & 368 & 859 \\
\hline$S 16$ & 135 & 318 & 63.6 & 15.9 & 759 & 475 & 713 \\
\hline
\end{tabular}


days, and 45 days under standard conditions. Three specimens were formed in each age, and the size of the specimens was $150 \mathrm{~mm} \times 150 \mathrm{~mm} \times 550 \mathrm{~mm}$. The side of each specimen was placed on a support, and the placement position was checked to ensure that the stress position of the specimen met the specified requirements. The loading speed was varied between 0.05 and $0.08 \mathrm{MPa} / \mathrm{s}$. When a specimen was at the edge of failure, the throttle of the testing machine was kept stable until the test ended, and the failure load was recorded. During the processing of test results, $115 \%$ and $85 \%$ of the mean values of three measured values were taken as the upper and lower limits, respectively. When only one of the measured values did not meet the specified requirements, the average value of the other two measured values was taken as the final result. When more than one of the measured values did not meet the specified requirements, the test was reperformed [29]. The test device is shown in Figure 2. The flexural strength of the concrete was calculated as

$$
f_{t}=\frac{\mathrm{Fl}}{\mathrm{bh}^{2}},
$$

where $f_{t}$ is the flexural strength of the concrete, $F$ is the maximum load at the time of concrete failure, $l$ is the distance of the support ( $\operatorname{span} ;=3 h$ ), $b$ is the width of the specimen section, and $h$ is the height of the specimen section.

\section{Results and Discussion}

3.1. Test Results. The flexural strengths of the concrete specimens of different ages are shown in Figure 3 and Table.4.

It can be seen from Figure 3 that the flexural strengths of the concrete specimens with different mixing proportions increased with the extension of the curing time. The flexural strength of the specimens varied significantly between 1 and $3 \mathrm{~d}$ and slightly between 28 and $45 \mathrm{~d}$, indicating that the increment of flexural strength gradually became smaller with the extension of the curing time [30].

\subsubsection{Influence of $W / B$ Ratio on Concrete Flexural Strength.} It is clear from Figure 4 that the flexural strength of the concrete decreased gradually with the increase of the $\mathrm{W} / \mathrm{B}$ ratio. The increase of the $\mathrm{W} / \mathrm{B}$ ratio was equivalent to the reduction of cementitious materials in the concrete. The shortage of cementitious materials led to an upward migration of the remaining water after the hydration reaction, forming a water film on coarse aggregates and reducing the bond strength between coarse aggregates and the cement mortar. Moreover, the loss of water formed a small water passage inside the concrete, leading to the formation of microcracks. Consequently, the compactness and interfacial bond strength of the structure were reduced, causing a decline in the flexural strength of the concrete [31].

\subsubsection{Influence of FA Content on Concrete Flexural Strength.} It is observable from Figure 5 that the flexural strength of the concrete first increased and then decreased with the increase of the FA content. When the FA content was 15\%, the flexural strength of the concrete reached a maximum, except for the specimen with 1-d curing age. This was because FA mainly participated in the hardening process of cementitious materials through the formation of microaggregates and particles [32]. The increase of the FA content reduced the proportion of cement and decreased the hydration rate of cement, causing a reduction in the flexural strength of the concrete.

\subsubsection{Influence of GGBFS Content on Concrete Flexural} Strength. After the addition of GGBFS into the concrete, gaps between cement particles were filled, the compactness was improved, and the flexural resistance was strengthened. GGBFS improved the early flexural strength of cement after the hydration reaction. GGBFS also reduced the calcium ion concentration between cement and coarse aggregates and increased the cementing performance between them. Thus, the flexural strength of the concrete was improved after the addition of GGBFS [6]. However, after a certain amount, GGBFS indirectly affected the hydration reaction of cement and reduced the flexural resistance (Figure 6).

\subsubsection{Influence of Sand Ratio on Concrete Flexural Strength.} It is observable from Figure 7 that the flexural strength of the concrete gradually increased with the increase of the sand ratio. With the increase of the sand ratio, micropores in the concrete were gradually filled with sand, and the compactness was also gradually improved; thus, the stiffness of the concrete was enhanced. However, the difference between the flexural strengths of the concrete specimens with the sand proportions of $37 \%$ and $39 \%$ was not very big. Taking the flexural strength of the $28 \mathrm{~d}$ specimen as an example, the flexural strengths for the sand proportions of $37 \%$ and $39 \%$ were 6.26 and $6.35 \mathrm{MPa}$ (only $1.44 \%$ increment), respectively. It indicates that the compactness of the concrete did not increase significantly when the sand ratio increased from $37 \%$ to $39 \%$.

\subsubsection{Influence of Gravel Gradation on Concrete Flexural} Strength. It is observable from Figure 8 that when gravel gradation increased from $3: 7$ to $4: 6$, the flexural strength of the concrete increased, and when it exceeded $4: 6$, the flexure strength gradually decreased. A proper gravel gradation could completely wrap the cement mortar on the surface of large and small gravels, enhance the adhesiveness between cement particles, make the internal distribution of each component of the concrete uniform, and improve the compactness by reducing the gap between cement particles. When there were insufficient small gravels and too many large gravels in coarse aggregates, the bonding strength between coarse aggregates and cement particles was affected, resulting in a reduction in the flexural strength [33]. However, when there were too many small gravels, coarse aggregates were affected; thus, the flexural strength of the concrete began to decrease. 


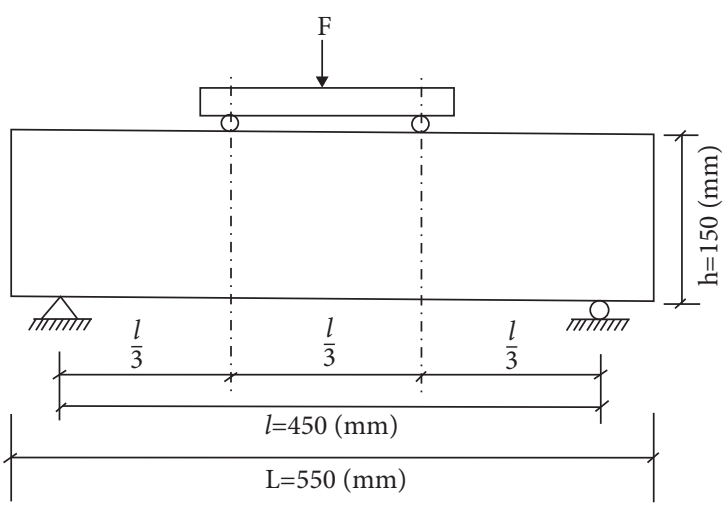

(a)

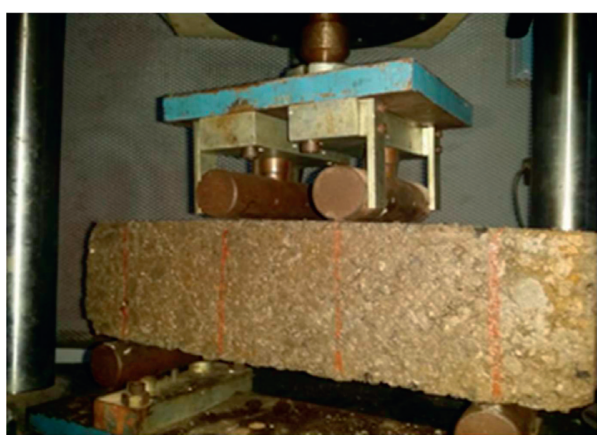

(b)

Figure 2: Flexural strength test setup. (a) Schematic diagram. (b) Test device.

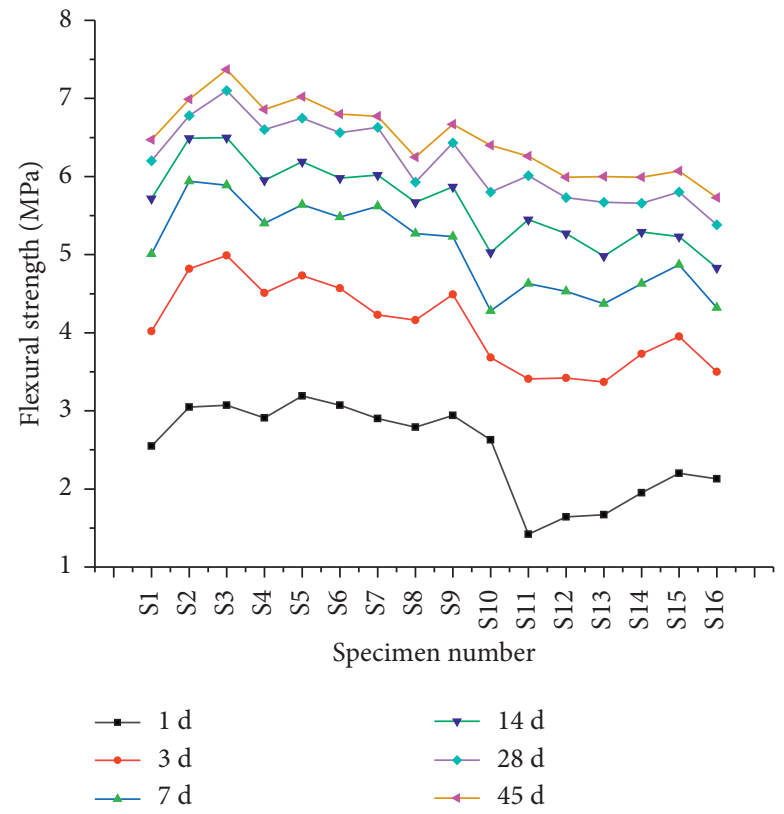

Figure 3: Variation of the flexural strengths of concrete specimens with different ages.

TABLE 4: Flexural strength of concrete at various ages.

\begin{tabular}{|c|c|c|c|c|c|c|}
\hline \multirow{2}{*}{ Specimen number } & \multicolumn{6}{|c|}{ Flexural strength $(\mathrm{MPa})$} \\
\hline & $1 \mathrm{~d}$ & $3 \mathrm{~d}$ & $7 \mathrm{~d}$ & $14 \mathrm{~d}$ & $28 \mathrm{~d}$ & $45 \mathrm{~d}$ \\
\hline$S 1$ & $2.55(0.01)$ & $4.02(0.12)$ & $5.01(0.14)(0.06)$ & $5.72(0.10)$ & $6.20(0.06)$ & $6.47(0.06)$ \\
\hline$S 2$ & $3.05(0.03)$ & $4.82(0.14)$ & $5.94(0.12)$ & $6.49(0.15)$ & $6.78(0.09)$ & $6.99(0.06)$ \\
\hline$S 3$ & $3.07(0.09)$ & $4.99(0.15)$ & $5.89(0.10)$ & $6.50(0.07)$ & $7.10(0.20)$ & $7.37(0.18)$ \\
\hline$S 4$ & $2.91(0.01)$ & $4.51(0.08)$ & $5.40(0.14)$ & $5.95(0.07)$ & $6.60(0.06)$ & $6.86(0.14)$ \\
\hline S5 & $3.19(0.02)$ & $4.73(0.10)$ & $5.64(0.15)$ & $6.19(0.14)$ & $6.75(0.12)$ & $7.02(0.20)$ \\
\hline S6 & $3.07(0.11)$ & $4.57(0.06)$ & $5.48(0.10)$ & $5.98(0.07)$ & $6.56(0.10)$ & $6.80(0.09)$ \\
\hline$S 7$ & $2.90(0.04)$ & $4.23(0.05)$ & $5.62(0.12)$ & $6.02(0.14)$ & $6.63(0.15)$ & $6.77(0.15)$ \\
\hline S8 & $2.79(0.06)$ & $4.16(0.07)$ & $5.27(0.14)$ & $5.67(0.07)$ & $5.93(0.09)$ & $6.25(0.06)$ \\
\hline$S 9$ & $2.94(0.03)$ & $4.49(0.06)$ & $5.23(0.06)$ & $5.87(0.15)$ & $6.43(0.14)$ & $6.67(0.20)$ \\
\hline$S 10$ & $2.63(0.02)$ & $3.68(0.09)$ & $4.28(0.08)$ & $5.03(0.08)$ & $5.80(0.08)$ & $6.40(0.12)$ \\
\hline$S 11$ & $1.42(0.01)$ & $3.41(0.06)$ & $4.63(0.14)$ & $5.45(0.14)$ & $6.01(0.09)$ & $6.26(0.09)$ \\
\hline$S 12$ & $1.64(0.02)$ & $3.42(0.04)$ & $4.53(0.10)$ & $5.27(0.10)$ & $5.73(0.14)$ & $5.99(0.12)$ \\
\hline
\end{tabular}


TABLE 4: Continued.

\begin{tabular}{|c|c|c|c|c|c|c|}
\hline \multirow{2}{*}{ Specimen number } & \multicolumn{6}{|c|}{ Flexural strength $(\mathrm{MPa})$} \\
\hline & $1 \mathrm{~d}$ & $3 \mathrm{~d}$ & $7 \mathrm{~d}$ & $14 \mathrm{~d}$ & $28 \mathrm{~d}$ & $45 \mathrm{~d}$ \\
\hline$S 13$ & $1.67(0.01)$ & $3.37(0.06)$ & $4.37(0.09)$ & $4.98(0.07)$ & $5.67(0.15)$ & $6.00(0.14)$ \\
\hline$S 14$ & $1.95(0.03)$ & $3.73(0.07)$ & $4.63(0.14)$ & $5.29(0.06)$ & $5.66(0.06)$ & $5.99(0.10)$ \\
\hline$S 15$ & $2.20(0.05)$ & $3.95(0.03)$ & $4.87(0.10)$ & $5.23(0.07)$ & $5.80(0.09)$ & $6.07(0.20)$ \\
\hline$S 16$ & $2.13(0.04)$ & $3.50(0.05)$ & $4.32(0.08)$ & $4.83(0.10)$ & $5.38(0.08)$ & $5.73(0.08)$ \\
\hline
\end{tabular}

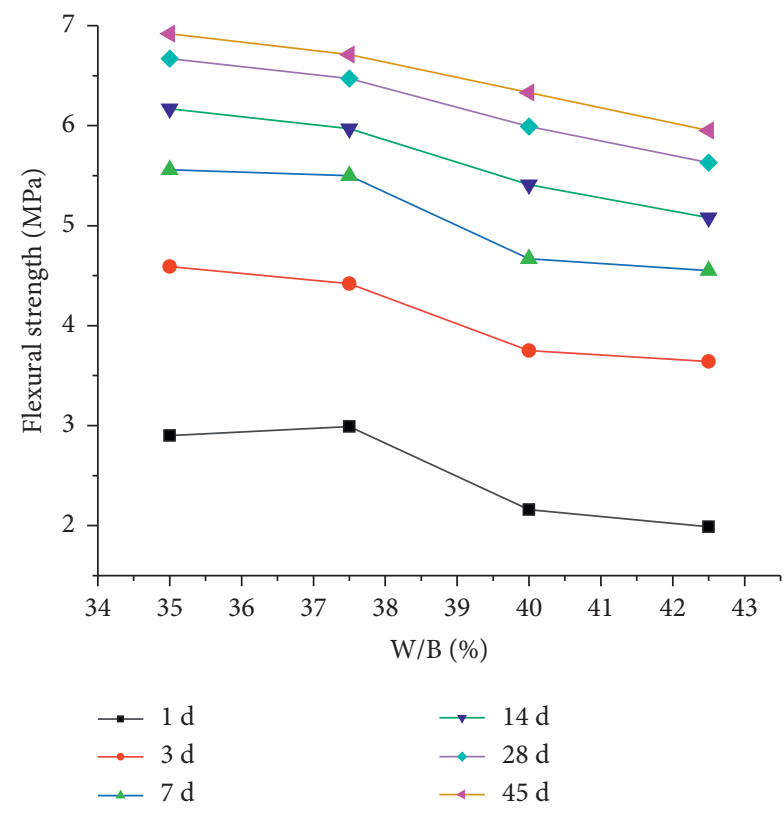

Figure 4: Influence of W/B ratio on concrete flexural strength.

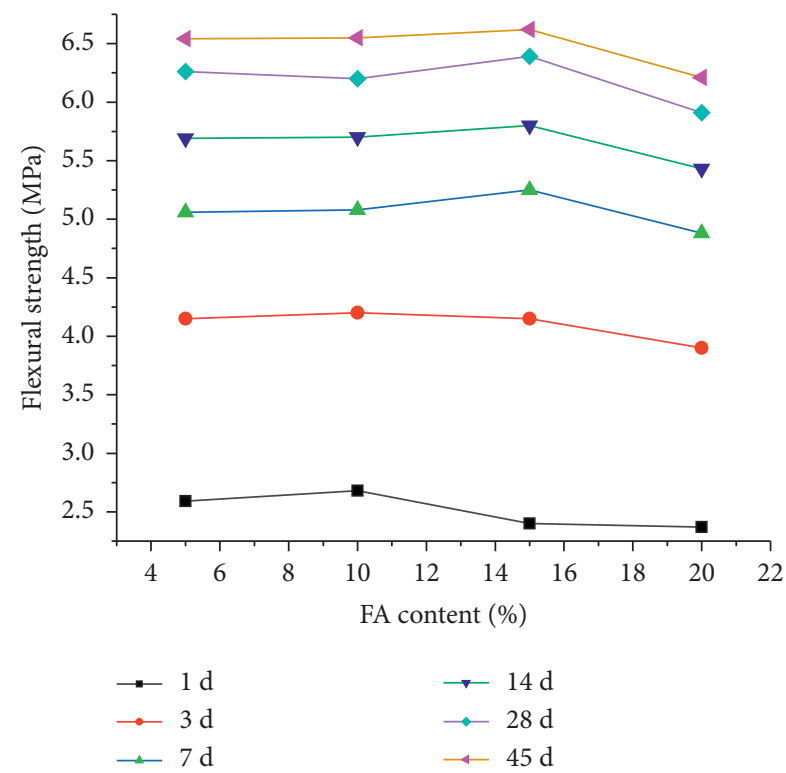

FIgURE 5: Influence of FA content on concrete flexural strength.

3.2. Range Analysis. Range analysis was carried out based on orthogonal test results, and the corresponding observations are presented in Table 5, where the $\mathrm{W} / \mathrm{B}$ ratio, the FA content, the GGBFS content, the sand ratio, and gravel gradation are termed as A, B, C, D, and E, respectively.

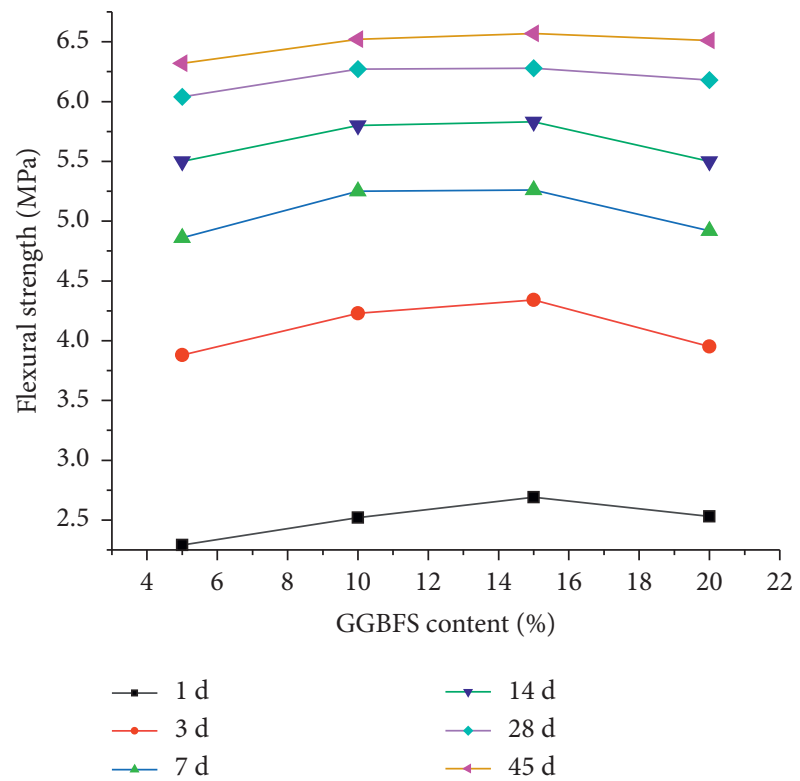

Figure 6: Influence of GGBFS content on concrete flexural strength.

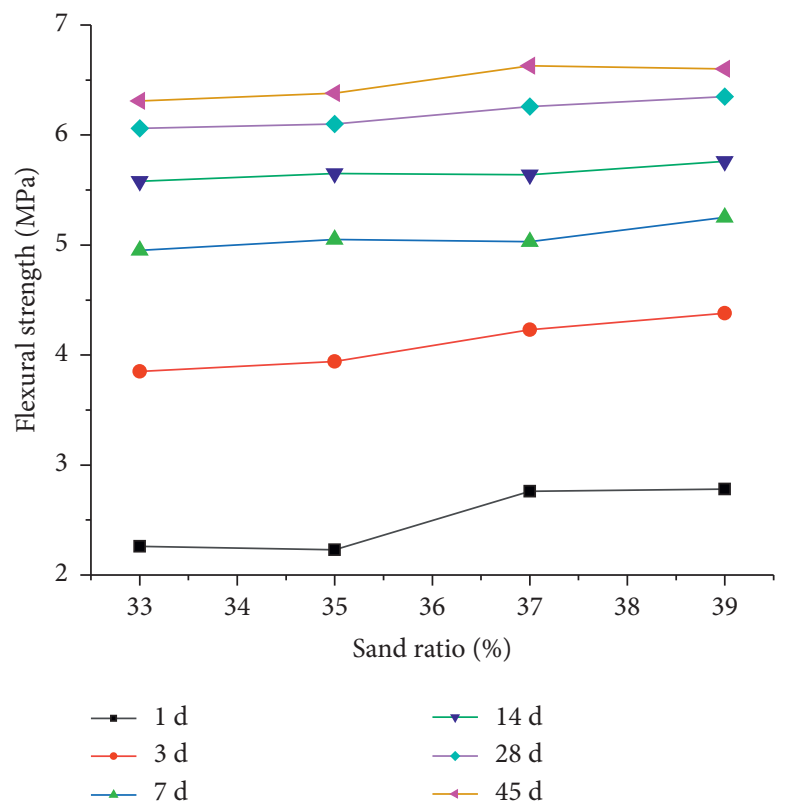

FIGURE 7: Influence of sand ratio on concrete flexural strength.

Now, comparing the $\mathrm{R}$ values of different influencing factors after $1 \mathrm{~d}$ of aging, it is detectable that $R_{A}>R_{D}>R_{E}=R_{C}>R_{B}$; thus, the order of the five influencing factors is W/B ratio $>$ Sand ratio $>$ Gravel 


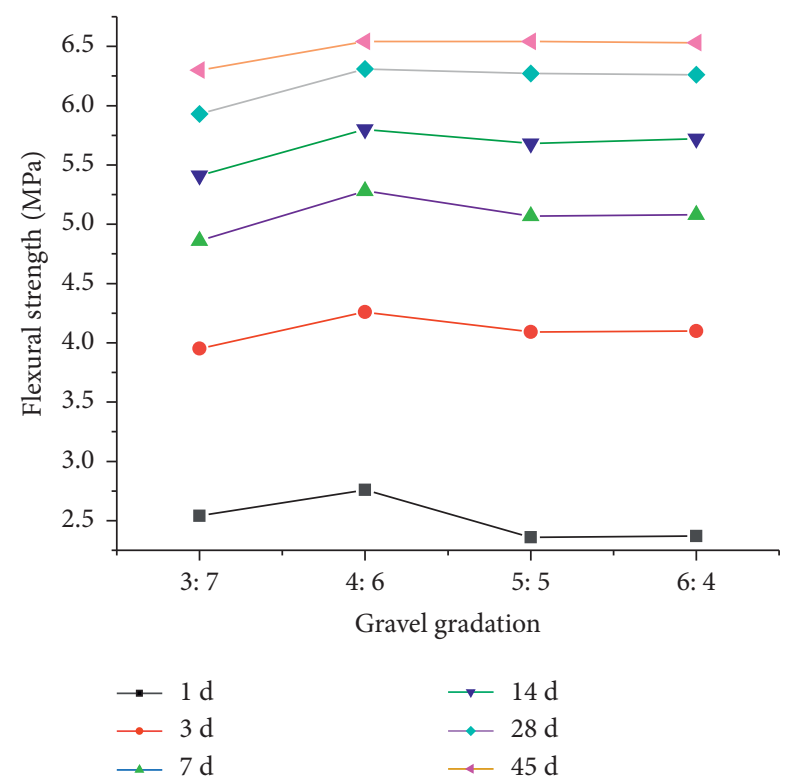

FIGURE 8: Influence of gravel gradation on concrete flexural strength.

gradation $>$ GGBFS content $>$ FA content. Similarly, after 3, $7,14,28$, and $45 \mathrm{~d}$ of aging, the trends were $\mathrm{W} / \mathrm{B}$ ratio $>$ Sand ratio $>$ GGBFS content $>$ Gravel gradation $>$ FA content, W/ B ratio $>$ Gravel gradation $>$ GGBFS content $>$ FA content $>$ Sand ratio, W/B ratio $>$ Gravel gradation $>$ FA content $>$ GGBFS content $>$ Sand ratio, W/B ratio $>$ Gravel gradation $>$ FA content $>$ Sand ratio $>$ GGBFS content, and $\mathrm{W} / \mathrm{B}$ ratio $>$ FA content $>$ Sand ratio $>$ GGBFS content $>$ Gravel gradation, respectively.

Further, by comparing the $K_{i}$ values, it was found that $K_{2}>K_{1}>K_{3}>K_{4}$ in the level of factor A, indicating that the flexural strength of the concrete reached a maximum when factor A was on the second level. Similarly, the optimal levels of factors B, C, D, and E were second, third, fourth, and second, respectively. Therefore, when the horizontal combination was $\mathrm{A} 2 \mathrm{~B} 2 \mathrm{C} 3 \mathrm{D} 4 \mathrm{E} 2$, the flexural strength of the concrete was the greatest under the consideration of a single action of the factors; therefore, this horizontal combination was the optimal preparation process combination to improve the flexural strength of the concrete after $1 \mathrm{~d}$ of aging. Similarly, the optimal mixing proportions of the concrete after $3,7,14$, 28, and $45 \mathrm{~d}$ of aging were A1B2C3D4E2, A1B3C3D4E2, $\mathrm{A} 1 \mathrm{~B} 3 \mathrm{C} 3 \mathrm{D} 4 \mathrm{E} 2, \mathrm{~A} 1 \mathrm{~B} 3 \mathrm{C} 3 \mathrm{D} 4 \mathrm{E} 2$, and A1B3C3D4E2, respectively. However, the A1B3C3D4E2 mixing proportion is recommended for engineering applications.

3.3. Analytic Hierarchy Process. The analytic hierarchy process (AHP) turns complex problems into easy-to-understand hierarchies. Range analysis used for orthogonal tests cannot obtain the influence level of each factor on test results. AHP can obtain the influence level of each factor and also the influence weight of each level [31]. Figure 9 shows the AHP model used in this experiment. The model was divided into three layers - the first layer contained the index of the test, the second layer consisted of different influencing factors, and the third layer was composed of the levels of different factors.
It was assumed that the average value of the sum of test data under the $j$ level of factor $N^{(i)}$ was $K_{\mathrm{ij}}$ (Table 5), and it was called the effect of the $j$ level of factor $N^{(i)}$ on the test ( $i=1(\mathrm{~A}), 2(\mathrm{~B}), 3(\mathrm{C}), 4(\mathrm{D}), 5(\mathrm{E}) ; j=1,2,3,4)$. Moreover, $M_{\mathrm{ij}}=K_{\mathrm{ij}}$; thus, three matrices were derived. Matrix $a$ presents the influence of horizontal layers on the test, matrix $s$ is the normalization of each column of matrix $a$, and matrix $c$ is a weight matrix representing the influences of different factors on the test.

$$
\begin{aligned}
& a=\left[\begin{array}{ccccc}
M_{11} & 0 & 0 & 0 & 0 \\
M_{21} & 0 & 0 & 0 & 0 \\
M_{31} & 0 & 0 & 0 & 0 \\
M_{41} & 0 & 0 & 0 & 0 \\
0 & M_{12} & 0 & 0 & 0 \\
0 & M_{22} & 0 & 0 & 0 \\
0 & M_{32} & 0 & 0 & 0 \\
0 & M_{42} & 0 & 0 & 0 \\
0 & 0 & M_{13} & 0 & 0 \\
0 & 0 & M_{23} & 0 & 0 \\
0 & 0 & M_{33} & 0 & 0 \\
0 & 0 & M_{43} & 0 & 0 \\
0 & 0 & 0 & M_{14} & 0 \\
0 & 0 & 0 & M_{24} & 0 \\
0 & 0 & 0 & M_{34} & 0 \\
0 & 0 & 0 & M_{44} & 0 \\
0 & 0 & 0 & 0 & M_{15} \\
0 & 0 & 0 & 0 & M_{25} \\
0 & 0 & 0 & 0 & M_{35} \\
0 & 0 & 0 & 0 & M_{45}
\end{array}\right], \\
& s=\left[\begin{array}{ccccc}
\frac{1}{t_{1}} & 0 & 0 & 0 & 0 \\
0 & \frac{1}{t_{2}} & 0 & 0 & 0 \\
0 & 0 & \frac{1}{t_{3}} & 0 & 0 \\
0 & 0 & 0 & \frac{1}{t_{4}} & 0 \\
0 & 0 & 0 & 0 & \frac{1}{t_{5}}
\end{array}\right], \\
& c=\left[\frac{R_{1}}{\sum_{i=1}^{5} R_{i}} \frac{R_{2}}{\sum_{i=1}^{5} R_{i}} \frac{R_{3}}{\sum_{i=1}^{5} R_{i}} \frac{R_{4}}{\sum_{i=1}^{5} R_{i}} \frac{R_{5}}{\sum_{i=1}^{5} R_{i}}\right] \text {. }
\end{aligned}
$$


TABLE 5: Range analysis of concrete flexural strength.

\begin{tabular}{|c|c|c|c|c|c|}
\hline $1 \mathrm{~d}$ & $A$ & $B$ & $C$ & $D$ & $E$ \\
\hline$K_{1}$ & 2.90 & 2.59 & 2.29 & 2.26 & 2.54 \\
\hline$K_{2}$ & 2.99 & 2.68 & 2.52 & 2.23 & 2.76 \\
\hline$K_{3}$ & 2.16 & 2.40 & 2.69 & 2.76 & 2.36 \\
\hline$K_{4}$ & 1.99 & 2.37 & 2.53 & 2.78 & 2.37 \\
\hline$R$ & 1.00 & 0.31 & 0.40 & 0.55 & 0.40 \\
\hline Better scheme (BS) & $\mathrm{A} 2$ & B2 & $\mathrm{C} 3$ & $\mathrm{D} 4$ & $\mathrm{E} 2$ \\
\hline Factor priority (FP) & \multicolumn{5}{|c|}{ ADECB/ADCEB } \\
\hline $3 \mathrm{~d}$ & $A$ & $B$ & $C$ & $D$ & $E$ \\
\hline$K_{1}$ & 4.59 & 4.15 & 3.88 & 3.85 & 3.95 \\
\hline$K_{2}$ & 4.42 & 4.20 & 4.23 & 3.94 & 4.26 \\
\hline$K_{3}$ & 3.75 & 4.15 & 4.34 & 4.23 & 4.09 \\
\hline$K_{4}$ & 3.64 & 3.90 & 3.95 & 4.38 & 4.10 \\
\hline$R$ & 0.95 & 0.30 & 0.47 & 0.53 & 0.31 \\
\hline BS & $A 1$ & $B 2$ & C3 & $D 4$ & E2 \\
\hline $\mathrm{FP}$ & \multicolumn{5}{|c|}{ ADCEB } \\
\hline $7 \mathrm{~d}$ & $A$ & $B$ & $C$ & $D$ & $E$ \\
\hline$\overline{K_{1}}$ & 5.56 & 5.06 & 4.86 & 4.95 & 4.86 \\
\hline$K_{2}$ & 5.50 & 5.08 & 5.25 & 5.05 & 5.28 \\
\hline$K_{3}$ & 4.67 & 5.25 & 5.26 & 5.03 & 5.08 \\
\hline$K_{4}$ & 4.55 & 4.88 & 4.92 & 5.25 & 5.08 \\
\hline$R$ & 1.01 & 0.37 & 0.40 & 0.30 & 0.42 \\
\hline BS & A1 & B3 & C3 & $\mathrm{D} 4$ & E2 \\
\hline $\mathrm{FP}$ & \multicolumn{5}{|c|}{ AECBD } \\
\hline $14 \mathrm{~d}$ & $A$ & $B$ & C & $D$ & $E$ \\
\hline$K_{1}$ & 6.17 & 5.69 & 5.50 & 5.58 & 5.41 \\
\hline$K_{2}$ & 5.97 & 5.70 & 5.80 & 5.65 & 5.80 \\
\hline$K_{3}$ & 5.41 & 5.80 & 5.83 & 5.64 & 5.68 \\
\hline$K_{4}$ & 5.08 & 5.43 & 5.50 & 5.76 & 5.72 \\
\hline $\mathrm{R}$ & 1.08 & 0.37 & 0.34 & 0.18 & 0.39 \\
\hline BS & $A 1$ & $B 3$ & C3 & $D 4$ & $E 2$ \\
\hline $\mathrm{FP}$ & \multicolumn{5}{|c|}{ AEBCD } \\
\hline $28 \mathrm{~d}$ & $A$ & $B$ & $C$ & $D$ & $E$ \\
\hline$K_{1}$ & 6.67 & 6.26 & 6.04 & 6.06 & 5.93 \\
\hline$K_{2}$ & 6.47 & 6.20 & 6.27 & 6.10 & 6.31 \\
\hline$K_{3}$ & 5.99 & 6.39 & 6.28 & 6.26 & 6.27 \\
\hline$K_{4}$ & 5.63 & 5.91 & 6.18 & 6.35 & 6.26 \\
\hline$R$ & 1.04 & 0.48 & 0.24 & 0.29 & 0.33 \\
\hline BS & $A 1$ & $B 3$ & C3 & $D 4$ & $E 2$ \\
\hline $\mathrm{FP}$ & \multicolumn{5}{|c|}{ ABEDC } \\
\hline $45 \mathrm{~d}$ & $A$ & $B$ & $C$ & $D$ & $E$ \\
\hline$K_{1}$ & 6.92 & 6.54 & 6.32 & 6.31 & 6.30 \\
\hline$K_{2}$ & 6.71 & 6.55 & 6.52 & 6.38 & 6.54 \\
\hline$K_{3}$ & 6.33 & 6.62 & 6.57 & 6.63 & 6.54 \\
\hline$K_{4}$ & 5.95 & 6.21 & 6.51 & 6.60 & 6.53 \\
\hline$R$ & 0.98 & 0.41 & 0.26 & 0.33 & 0.24 \\
\hline BS & A1 & B3 & C3 & $\mathrm{D} 4$ & $\mathrm{E} 2 / \mathrm{E} 3$ \\
\hline FP & \multicolumn{5}{|c|}{ ABDCE } \\
\hline
\end{tabular}




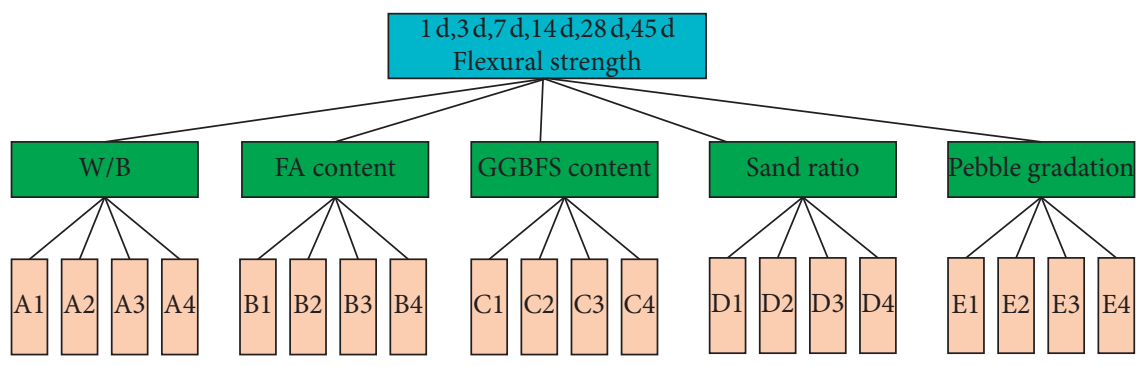

Figure 9: AHP model for the flexural strength test.

Now, $t_{j}=\sum_{i=1}^{5} M_{\mathrm{ij}}(j=1,2,3,4)$; hence, the weight of each factor level of the test index was $\omega=\operatorname{asc}^{T}$. The data presented in Table 4 were substituted into the matrix. Among the four levels of the W/B ratio, A1 (35\%) had the largest weight. Among the four levels of FA content, when the age was $1 \mathrm{~d}$, B2 (10\%) had the largest weight. When the ages were 7 and $14 \mathrm{~d}, \mathrm{~B} 4(20 \%)$ and B3 (15\%) had the largest weight, respectively. As the curing time increased, the weight of the influence of FA on flexural strength gradually increased. Among the four levels of GGBFS content, when the age was $1 \mathrm{~d}, \mathrm{C} 3(15 \%)$ had the largest weight. When the age was $7 \mathrm{~d}$, C2 (10\%) and C4 (20\%) had the largest weight. When the age reached $14 \mathrm{~d}$, the weight of $\mathrm{C} 3$ again $(15 \%)$ became the largest. Among the four levels of sand ratio, D4 (39\%) had the largest weight, and among the four levels of gravel gradation, E2 (40\%:60\%) had the largest weight. Therefore, the optimal values of W/B ratio, FA content, GGBFS content, sand ratio, and gravel gradation were $35 \%, 15 \%, 15 \%$, $39 \%$, and $40 \%: 60 \%$, respectively.

Range analysis and AHP were used to analyze the influences of different factors on the flexural strength of the concrete. It is clear that the effects of each factor on concrete flexural strength were significantly different at different ages. Among the five factors, the W/B ratio had the greatest influence on the flexural strength of the concrete. With the increase of the $\mathrm{W} / \mathrm{B}$ ratio, the flexural strength of the concrete gradually decreased. FA mainly played a role in the later stage of concrete setting and hardening, and with the increase of the FA content, the flexural strength of the concrete first increased and then decreased. GGBFS played a role mainly in the early stage of concrete curing. With the increase of the GGBFS content, concrete flexural strength first increased and then decreased. The sand ratio also played a more obvious role in the early stage of concrete curing. The flexural strength of the concrete also increased as the sand ratio increased. Gravel gradation mainly played a role in the middle stage of concrete curing. The flexural strength of the concrete first increased and then decreased with the increase of the amount of small gravels.

It is clear from Figure 10 that the flexural strength change of the concrete caused by the W/B ratio was always the largest in all six ages [34], indicating that the effect of $\mathrm{W} / \mathrm{B}$ was the greatest among the five influencing factors. This was because cementitious materials included cement, FA, and GGBFS. These three materials constantly changed their form and characteristics with the extension of the aging period and "actively" participated during concrete hardening [33]. Cement in cementitious materials continuously underwent a hydration reaction and generated compounds to improve the flexural strength of the concrete. GGBFS played a role in the early stage of curing and enhanced the early flexural strength of the concrete. The positive role of FA was noticed in the later stage of curing, and it improved the flexural strength.

The influence of FA content on the flexural strength of the concrete was not significant during $1-7 \mathrm{~d}$ of curing. However, with the extension of the aging time, FA greatly influenced the flexural strength, and this phenomenon was related to the mineral composition of FA. FA mainly consisted of $\mathrm{SiO}_{2}, \mathrm{Al}_{2} \mathrm{O}_{3}, \mathrm{Fe}_{2} \mathrm{O}_{3}, \mathrm{CaO}$, and other components. These elements had certain activities and reacted with $\mathrm{Ca}^{2+}$ ions after cement hydration to form C-S-H, which coated FA and formed a porous structure between cement and fly ash. Therefore, FA could not completely react with the cement hydration products in the early stage and manifested a low influencing degree on the flexural strength. However, a secondary reaction began, because the coated FA was gradually decomposed and formed more stable compounds, thus enhancing the flexural strength of the concrete $[6,32]$.

The influence level of GGBFS was always higher than that of FA in the early stage. This was because $\mathrm{Ca}^{2+}$ ions produced by the hydration reaction became enriched at internal interfaces of the concrete. Active $\mathrm{SiO}_{2}$ atoms of GGBFS reacted with $\mathrm{Ca}^{2+}$ ions and generated stable C-S-H, thus increasing the flexural strength of the concrete. However, with the extension of the curing time, the content of GGBFS decreased continuously; thus, its influence level began to decline. At this time, FA gradually replaced GGBFS and reacted with unstable compounds in the concrete, improving the flexural strength. Therefore, the influence level of GGBFS was less than that of FA in the later stage.

Fine sand particles filled the gaps between the cementitious materials and coarse aggregates and increased the flexural strength by improving the internal compactness of the concrete $[35,36]$. In the early stage, the cement hydration reaction was slow; thus, the cement slurry and coarse aggregates could not set well with each other. Therefore, the sand ratio played a significant role in improving the flexural strength during $1-3 \mathrm{~d}$ of curing. The internal integrity of the concrete was gradually improved with the extension of the curing time; thus, the cementing performance between materials was continuously enhanced, and the effects of FA and gravels were gradually revealed. In the later stage, the flexural strength of the concrete increased steadily, and the importance of W/B, coarse aggregates, and other materials decreased slightly; however, the influence of the sand ratio increased. 


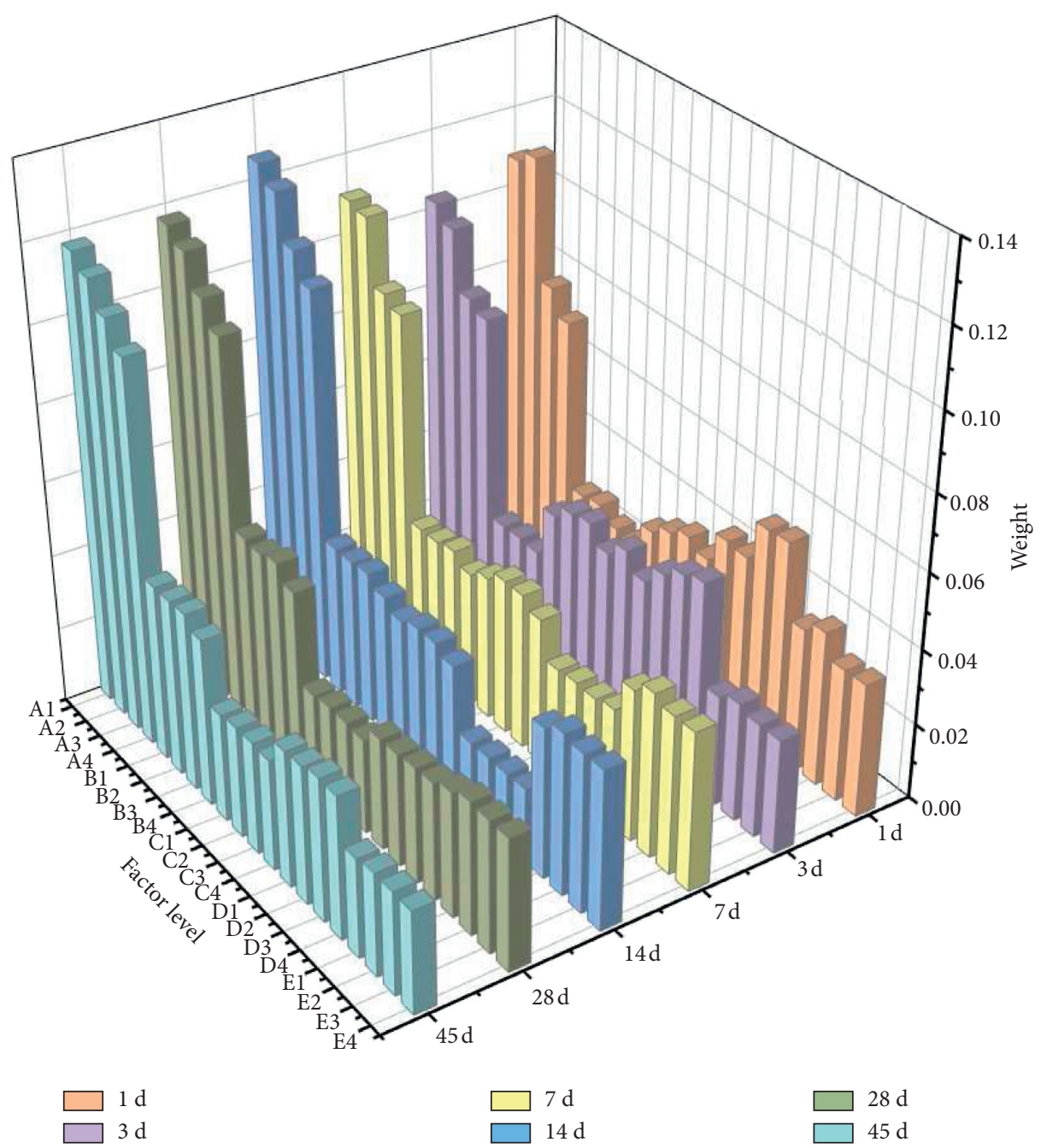

Figure 10: Influence weight of each factor level on the test index.

The influence of gravel gradation first increased and then decreased with the extension of the curing time. The increase and decrease of the proportion of coarse aggregates were closely related to the increase of flexural strength. The bond strength between coarse aggregates and cement stones manifested a significant effect on the interfacial bond strength. With the extension of the curing time, the amount of stable materials generated in the concrete gradually increased, and the growth range of the bond strength between coarse aggregates and cement stones also increased, thus improving the flexural strength of the concrete. After $28 \mathrm{~d}$ of curing, the growth rate of the bond strength between coarse aggregates and cement stones slowed down; thus, the effect of coarse aggregates on flexural strength decreased.

\section{Prediction Model for Concrete Flexural Strength Based on Machine Learning}

It is discernible from Figures $6-10$ that the relationship between the five factors and the flexural strength of the concrete was nonlinear; therefore, it is necessary to establish a multivariate nonlinear regression model to quantify the influences of these five factors on the flexural strength of the concrete. In this analysis, BPNN and SVM were used to optimize the prediction model by adjusting relevant parameters and functions. The W/B ratio, FA content, GGBFS content, sand ratio, gravel gradation, and aging time were used as input data of the input layer, and the flexural strength of the concrete was the output layer data. A total of 96 sets of data were used to form a database; in order to avoid the overfitting of data, a stratified 20-fold cross-validation was used to set the training model; Figure 11 showed a schematic description of the cross-validation. The designing and testing of these two machine learning models were performed in Matlab 2018b.

\subsection{Prediction Model Structure}

4.1.1. SVM. SVM, as an intelligent algorithm, can overcome nonlinear problems and is suitable for small samples [37]. The process of flexural strength prediction was performed using a kernel function to learn the relationship between the input index and the output index. In the SVM model, the kernel function defined in the high-dimensional feature 


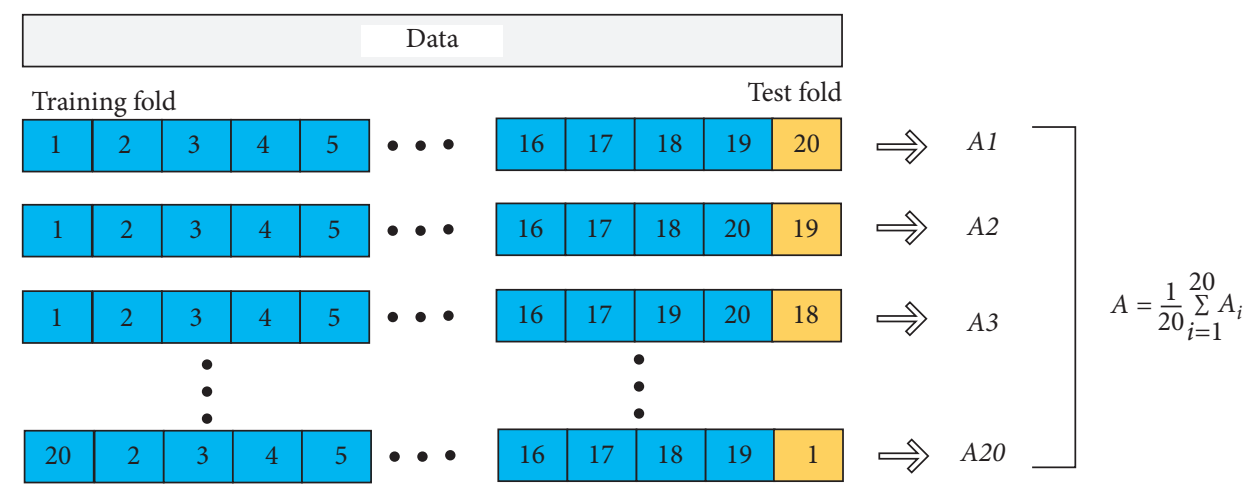

Figure 11: Schematic description of 20 -fold validation.

space was used to estimate regression. The kernel function was mapped from the low-dimensional space to the highdimensional space, so that the input had a nonlinear performance (Figure 12). Based on statistical learning theory, the SVM model performed regression estimation through risk minimization. Vapnik's $\mathcal{E}$-insensitive loss function was used to measure the risk. The risk function consisting of an empirical error and a confidence level value was minimized by the structural risk minimization principle [38].

4.1.1.1. Kernel Function. The Kernel function has a great influence on the prediction accuracy of SVM. In different prediction models, an appropriate kernel function should be selected according to research characteristics [39]. The Gaussian kernel function was used for the prediction model due to its advantages of radial basis kernel function and good antijamming ability.

4.1.1.2. Implementation Steps. First, a sample dataset of the model with $\mathrm{N}$ degrees of freedom was given: $\left(x_{1}, y_{1}\right)$, $\left.\left(x_{2}, y_{2}\right), \ldots,\left(x_{n}, y_{n}\right)\right\}$, where $x_{i}$ is the input vector (prediction vector), and $y_{i}$ is the output vector (target vector). The set of $x_{i}$ and $y_{i}$ was a subset of the population $P(x, y)$ of unknown probability density distribution. Moreover, $x_{i}$ was mapped to a high-dimensional feature space by the nonlinear function $\varphi\left(x_{i}\right)$, and linear regression was then carried out in the high-dimensional space. The relationship between the prediction vector and the target vector was simulated by the fitting function $f(x)=\omega^{T} \times \varphi(x)+b$, where $\omega$ and $b$ are parameters.

4.1.2. BPNN. BPNN was mainly composed of two processes: signal forward propagation and error backpropagation. The input layer was processed by the hidden layers and then propagated to the output layer. The error between the output value and the actual value was transmitted to the input layer through the hidden layer, so that each unit could share the error. Further, through repeated weight adjustments, the required prediction accuracy was achieved [35]. The structure of the BPNN model shown in Figure 13 includes one input layer, one output layer, and several hidden layers [40].

(1) Hidden Layer of BPNN. Generally, a hidden layer has one or two layers. According to the Kolmogorov theorem, a simple BPNN with only one hidden layer can approximate a nonlinear continuous function of any complexity degree with arbitrary accuracy on a closed set. In practical applications, the number of hidden layers is generally determined by comparing network training accuracies under different hidden layers [41]. After repeated tests, a hidden layer was used in this analysis, constituting a network structure of " $1+1+1$."

The number of hidden layer nodes was determined as $N=\sqrt{n+m}+a$, where $N$ is the number of hidden layer nodes, $n$ is the number of input layer nodes, $m$ is the number of output layer nodes, and $a$ is a constant between 1 and 10 [42]. This equation was used in combination with a trial-and-error method to improve the network performance. The hidden layer was iterated with the number of nodes from 3 to 13 until an optimal network performance was achieved. The optimal minimize number of nodes in the hidden layer was selected as 10 .

(2) Determination of Transfer Function and Training Algorithm. (1) Transfer function: in order to select the transfer function, a typical design of BPNN was adopted. The logSigmoid function was adopted as the transfer function in the hidden layer, and the output layer used a linear transfer function, because its output value could be arbitrarily assigned as an output function [42]. (2) Training algorithm: a traditional BPNN belongs to the fastest descent method, which has a low learning efficiency and easily falls into a local minimum point. The Levenberg-Marquardt rule is suitable for solving large- and medium-scale problems, because one iteration can significantly reduce the error [43].

4.2. Analysis of Prediction Results. In order to verify the prediction accuracy of the model, the mean square error (MSE), root mean square error (RMSE), and the goodness of fit $\left(R^{2}\right)$ were evaluated. The MSE reflected the degree of dispersion between predicted and actual values, and RMSE is the standard value of MSE, whereas $R^{2}$ verified the degree of fit between predicted and actual values. 


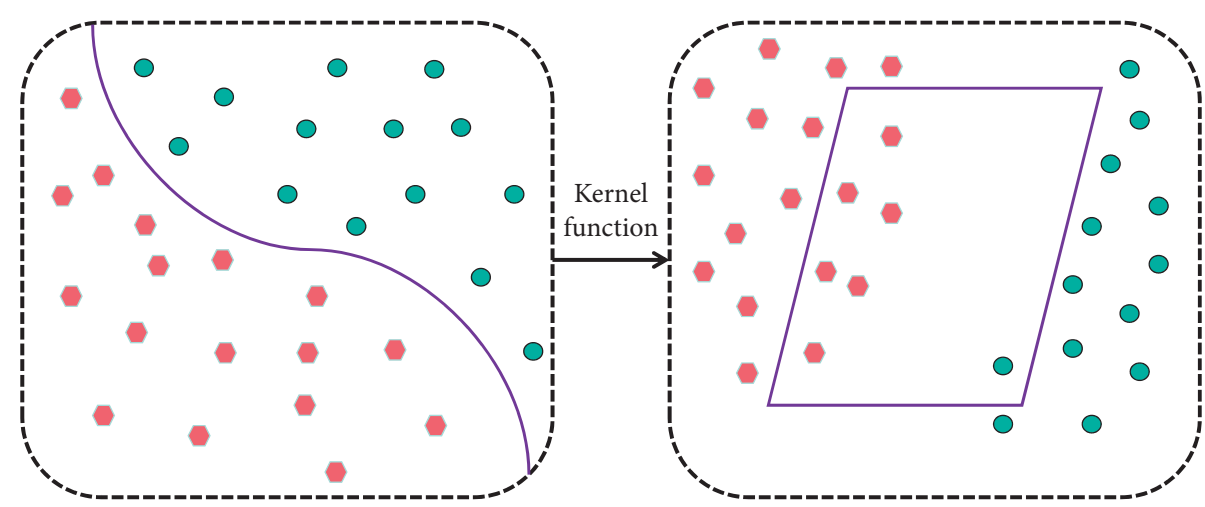

FIgURE 12: Nonlinear mapping in SVM.

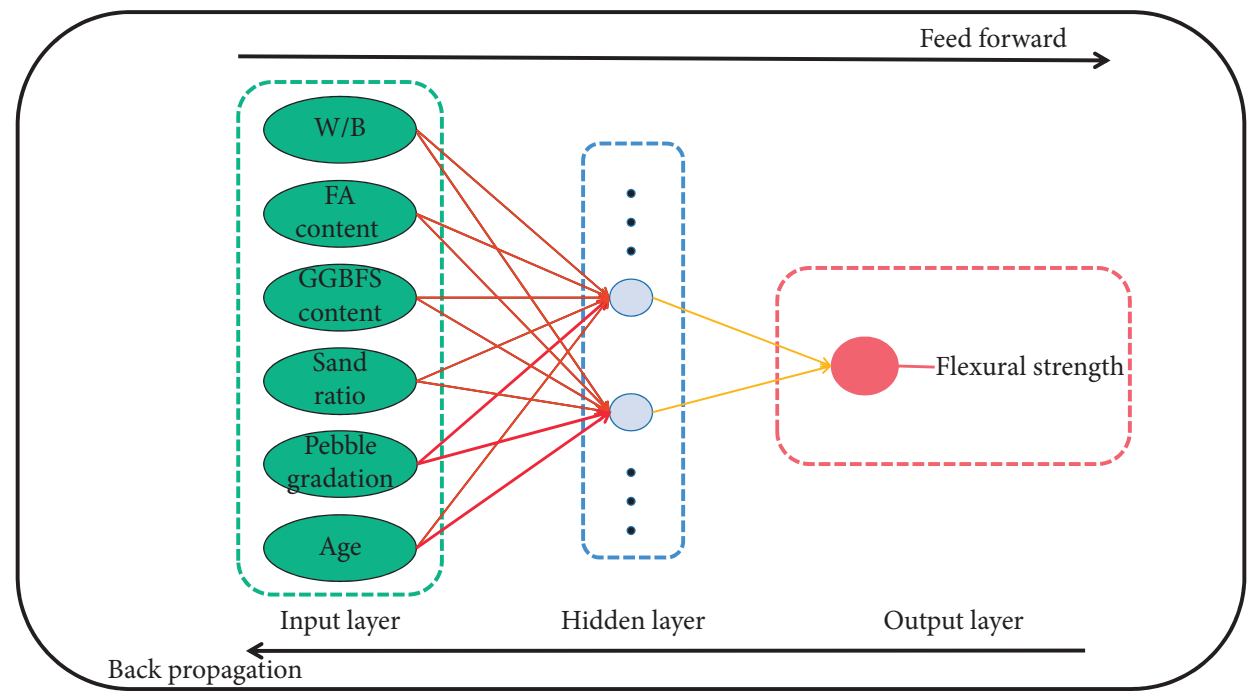

FIGURE 13: BPNN structure.

$$
\begin{aligned}
\text { MSE } & =\frac{\sum_{i=1}^{n}\left(y_{\mathrm{obs}}-y_{\mathrm{pred}}\right)^{2}}{n}, \\
\mathrm{RMSE} & =\sqrt{\frac{\sum_{i=1}^{n}\left(y_{\mathrm{obs}}-y_{\mathrm{pred}}\right)^{2}}{n}}, \\
R^{2} & =1-\frac{\sum_{i=1}^{n}\left(y_{\mathrm{obs}}-y_{\mathrm{pred}}\right)^{2}}{\sum_{i=1}^{n}\left(y_{\mathrm{obs}}-y_{\mathrm{obs}}^{-}\right)^{2}},
\end{aligned}
$$

where $y_{\mathrm{obs}}$ is the observed value, $\overline{y_{\mathrm{obs}}}$ is the average observed value, and $y_{\text {pred }}$ is the predictive value.

4.2.1. Prediction Results Comparison between BPNN and $S V M$. The performance of the BPNN model was verified by comparing it with the SVM model. From Table 6 and Figure 14, it can be seen that both the SVM model and the BPNN model have high accuracy, but in comparison, the $R^{2}$ for the SVM training set is 0.883 , the $R^{2}$ for the BPNN training set is 0.888 , the MSE for the SVM testing set is 0.332 , and $R^{2}$ is 0.841 , and the MSE for the BPNN testing set is 0.143 , and $R^{2}$ is 0.927 . Based on these observations, it can be concluded that BPNN outperforms the SVM model in predicting the data in both the training and testing sets.

Table 7 and Figure 15 show the number of samples and corresponding percentage in the error range from BPNN and SVM, and the model with the most frequent value of misprediction rate was taken as the model presented in the paper. These key statistics showed that the BPNN model has higher predictive ability compared with SVM model. The percentages of BPNN model training set and test set prediction error range of $5 \%$ are $93.9 \%$ and $92.7 \%$, respectively, while the SVM model values are 89.25 and 88.5 .

Because the basic principles of BPNN and SVM are different, and the operating mechanism is also inconsistent, the significant difference analysis of the model prediction results can better analyze and compare the results. The SPSS 21.0 software was used to test the significance of the difference in the prediction results, the $t$-test method was selected to compare the significant difference between the two methods, and the $P$ value was $0.28>0.05$, indicating that there is no significant difference in the fitting results of the two methods. Although there is no significant difference in 
TABLE 6: Evaluation parameters of machine learning methods.

\begin{tabular}{lccc}
\hline & MSE & RMSE & $R^{2}$ \\
\hline BPNN train & 0.250 & 0.500 & 0.888 \\
BPNN test & 0.143 & 0.364 & 0.927 \\
SVM train & 0.262 & 0.507 & 0.883 \\
SVM test & 0.322 & 0.547 & 0.841 \\
\hline
\end{tabular}

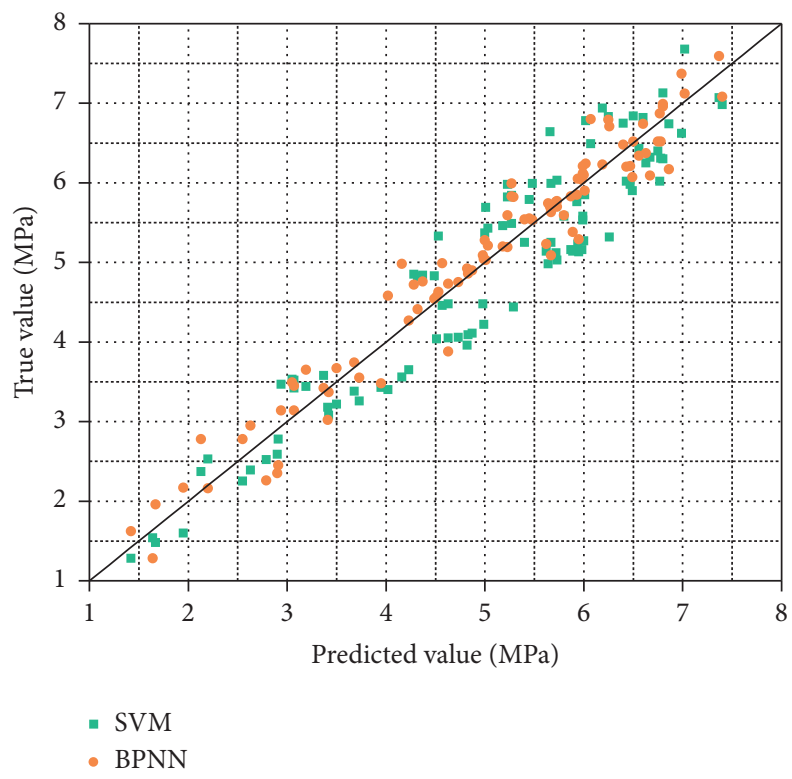

Figure 14: The correlation between actual and predicted output using the machine learning methods.

TAвLE 7: Number of samples and corresponding percentage in the error range from machine learning predictions.

\begin{tabular}{lccccccc}
\hline \multirow{2}{*}{ Error range(\%)) } & \multicolumn{2}{c}{ SVM } & \multicolumn{3}{c}{ BPNN } \\
& No of train & $\%$ & No of test & $\%$ & No of train & $\%$ & No of test \\
\hline 5 & 1628 & 89.25 & 85 & 88.5 & 1712 & 93.9 & 89 \\
10 & 121 & 6.63 & 5 & 5.2 & 89 & 4.88 & 8 \\
15 & 45 & 2.47 & 4 & 4.2 & 17 & 0.93 & 4 \\
20 & 30 & 1.64 & 2 & 2.1 & 6 & 0.32 & 3 \\
\hline
\end{tabular}

the results between the two modeling methods, BPNN was more suitable for the prediction of the flexural strength of the concrete, because there are higher requirements for prediction accuracy of concrete strength.

4.2.2. Prediction Results Comparison with the Empirical Equation. Existing flexural strength prediction models are mainly determined by the compressive strength of concretes. The Chinese code [44] presents a relationship between the compressive strength and flexural strength of concrete, and we compared the prediction accuracy of machine learning methods and empirical formulas for the 28-day flexural strength of concrete, which was calculated from the machine learning method and the compressive strength in literature [45], respectively. The test results are shown in Table 8.

Since only the relationship between compressive strength and flexural strength of concrete at 28 days of age is given in the specification, the predicted results of 28-day concrete flexural strength in machine learning methods are also chosen for comparison, and the results showed that the BPNN model still has the highest accuracy. Meanwhile, the $t$-test results indicated that there is a significant difference between the machine learning prediction results and the empirical equation prediction results. Furthermore, the use of machine learning methods can avoid complicated 


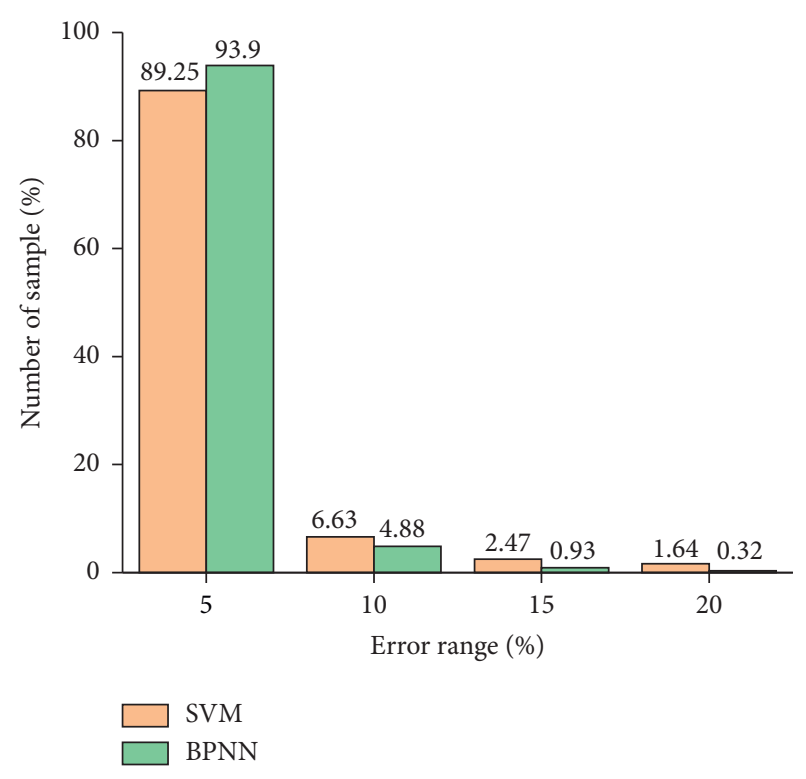

(a)

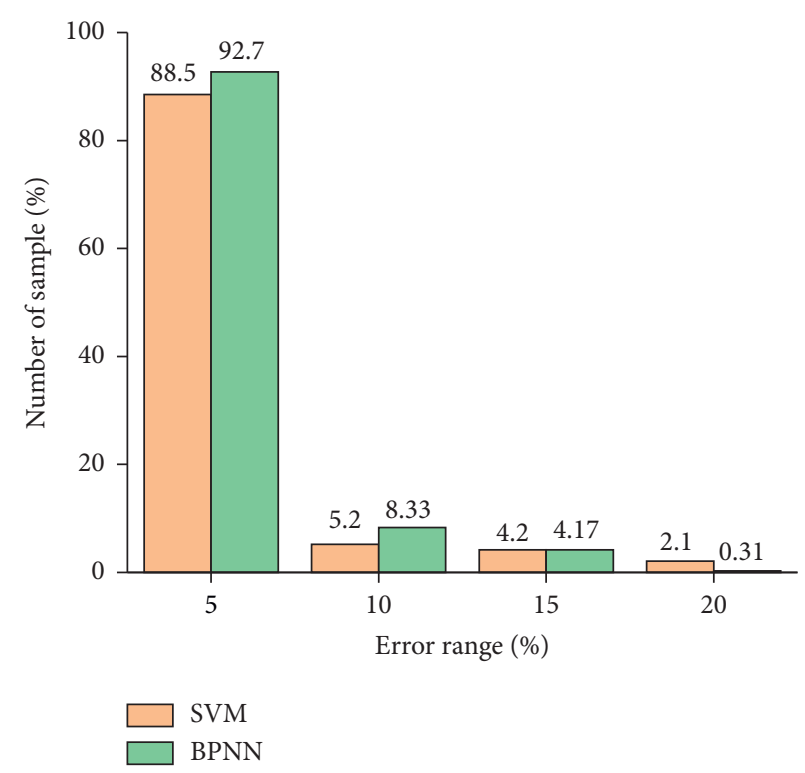

(b)

FIgURE 15: Distribution of the errors from machine learning methods. (a) Training. (b) Testing.

TABle 8: Evaluation parameters of machine learning methods and empirical equation.

\begin{tabular}{lccr}
\hline & MSE & RMSE & $R^{2}$ \\
\hline Empirical equation & 0.114 & 0.338 & 0.720 \\
SVM & 0.050 & 0.223 & 0.876 \\
BPNN & 0.037 & 0.193 & 0.909 \\
\hline
\end{tabular}

experiments and reduce the error of human intervention, so the BPNN model is recommended as a prediction tool for the flexural strength of concrete when the data type is similar to this research.

\section{Conclusions}

Orthogonal experiments were performed to study the flexural strength of an eco-friendly concrete containing FA and GGBFS. The effects of $\mathrm{W} / \mathrm{B}$ ratio, FA content, GGBFS content, sand ratio, and gravel gradation on the flexural strength of the concrete were investigated by range analysis and hierarchy analysis. In addition, two machine learning models were proposed to predict the flexural strength of the concrete. The main observations of this research are summarized below.

The effects of different factors and different levels of each factor on the flexural strength of the concrete were analyzed, and the optimal mixing proportions of the concrete for six different ages were also determined. The optimal values of $\mathrm{W} / \mathrm{B}$ ratio, FA content, GGBFS content, sand ratio, and gravel gradation were $35 \%, 15 \%, 15 \%, 39 \%$, and $40 \%: 60 \%$, respectively.

The $\mathrm{W} / \mathrm{B}$ ratio had the greatest effect on the flexural strength of the concrete. With the increase of $\mathrm{W} / \mathrm{B}$, the flexural strength of the concrete decreased gradually. The early stage of concrete curing was mainly influenced by the GGBFS content and the sand ratio. GGBFS manifested a strong activity by consuming $\mathrm{Ca}^{2+}$ ions in the concrete. The flexural strength of the concrete first increased and then decreased with the increase of the GGBFS content. The sand ratio had a positive role in the improvement of the flexural strength of the concrete.

Gravel gradation had a greater influence in the middle stage of concrete curing. The flexural strength of the concrete first increased and then decreased with the increase of the content of small gravels. FA mainly played a role in the later stage of concrete curing, because C-S-H initially covered the surface of FA, and the flexural strength of the concrete first increased and then decreased with the increase of the FA content.

The BPNN and SVM models both had higher accuracy than the empirical equation after 20 -fold cross-validation. However, the BPNN model was more accurate than the SVM model, while there is no significant difference in the fitting results of the two methods. Thus, BPNN was more suitable for the prediction of the flexural strength of the concrete, because there are higher requirements for prediction accuracy of concrete strength.

The established model has a good adaptability in this research. In the future, future verification of the trained machine learning models on more mix proportions and curing conditions needs to be conducted. Moreover, 
some machine learning models with higher prediction accuracy deserve to be built as much as complexity allows.

\section{Data Availability}

The data used to support the findings of this study are available from the corresponding author upon request.

\section{Conflicts of Interest}

The authors declare no conflicts of interest regarding the publication of this paper.

\section{Acknowledgments}

This research was funded by the Key Project of Water Conservancy Science and Technology of Henan Province (Grant no. GG202062).

\section{References}

[1] P. Rashiddadash, A. A. Ramezanianpour, and M. Mahdikhani, "Experimental investigation on flexural toughness of hybrid fiber reinforced concrete (HFRC) containing metakaolin and pumice," Construction and Building Materials, vol. 51, pp. 737-738, 1953.

[2] R. Liu, H. Li, Q. Jiang, and X. Meng, "Experimental investigation on flexural properties of directional steel fiber reinforced rubberized concrete," Structure, vol. 27, pp. 1660-1669, 2020.

[3] O. Karahan, "Transport properties of high volume fly ash or slag concrete exposed to high temperature," Construction and Building Materials, vol. 152, pp. 898-906, 2017.

[4] D. Ravina and P. K. Mehta, "Properties of fresh concrete containing large amounts of fly ash," Cement and Concrete Research, vol. 16, no. 2, pp. 227-238, 1986.

[5] P. K. Mehta, G. M. Giaccio, and V. M. Malhotra, "Concrete incorporating high volumes of ASTM class F fly ash," Cement, Concrete and Aggregates, vol. 10, no. 2, 1988.

[6] M. Nili and M. Tadayon, "The relationship between setting time and early age strength of concrete containing silica fume, fly ash and slag," in Proceedings of the The Third International Conference on Sustainable Construction Materials and Technologies, pp. 19-21, the University of Kyoto, Kyoto Research Park, Kyoto, Japan, August 2013.

[7] G. L. Golewski, "Estimation of the optimum content of fly ash in concrete composite based on the analysis of fracture toughness tests using various measuring systems," Construction and Building Materials, vol. 213, pp. 142-155, 2019.

[8] G. L. Golewski, "Effect of curing time on the fracture toughness of fly ash concrete composites," Composite Structures, vol. 185, pp. 105-112, 2018.

[9] C. D. Atis, "High-volume fly ash concrete with high strength and low drying shrinkage, "high-volume fly ash concrete with high strength and low drying shrinkage," Journal of Materials in Civil Engineering, vol. 15, no. 2, pp. 153-156, 2003.

[10] P. Wedding, F. Hogan, and J. Meusel, "Evaluation for durability and strength development of a ground granulated blast furnace slag," Cement, Concrete and Aggregates, vol. 3, no. 1, p. 40, 1981.
[11] D. M. Roy and D. M. ldorn, "Hydration structure, and properties of blast furnace slag cements,mortars, and concrete," ACI Journal Proceedings, vol. 79, pp. 444-457, 1982.

[12] V. Sivasundaram and V. M. Malhotra, "Properties of concrete incorporating low quantity of cement and high volumes of ground granulated slag," ACI Materials Journal, vol. 89, pp. 554-563, 1992.

[13] J. M. Khatib and J. J. Hibbert, "Selected engineering properties of concrete incorporating slag and metakaolin," Construction and Building Materials, vol. 19, no. 6, pp. 460-472, 2005.

[14] B. H. Bharatkumar, B. K. Raghuprasad, D. S. Ramachandramurthy, R. Narayanan, and S. Gopalakrishnan, "Effect of fly ash and slag on the fracture characteristics of high performance concrete," Materials and Structures, A, Structural Materials Properties, Microstructure and Processing, vol. 528, no. 4-5, pp. 2149-2157, 2011.

[15] Z. Ali, R. Shadi, A. Nazari, and S. Riahi, "Effects of $\mathrm{Al}_{2} \mathrm{O}_{3}$ nanoparticles on properties of self compacting concrete with ground granulated blast furnace slag (GGBFS) as binder," Science China Technological Sciences, vol. 54, no. 9, pp. 2327-2338, 2011.

[16] N. Ali and R. Shadi, "The role of $\mathrm{SiO} 2$ nanoparticles and ground granulated blast furnace slag admixtures on physical, thermal and mechanical properties of self compacting concrete," Materials Science and Engineering, vol. 528, pp. 2149-2157, 2011.

[17] N. Ali and R. Shadi, "The effects of $\mathrm{TiO} 2$ nanoparticles on physical, thermal and mechanical properties of concrete using ground granulated blast furnace slag as binder," Materials Science and Engineering, vol. 528, pp. 085-2092, 2011.

[18] N. Ali and R. Shadi, "The effects of $\mathrm{ZnO}_{2}$ nanoparticles on properties of concrete using ground granulated blast furnace slag as binder," Journal of Composite Materials, vol. 46, no. 9, pp. 1079-1090, 2011.

[19] J. Zheng and G. Liu, "The influence and application of slag, fly ash, and limestone flour on compressive strength of concrete based on the concrete compressive strength development over time (CCSDOT) model," Applied Sciences, vol. 10, Article ID 3572, 3572 pages, 2020.

[20] S. Chithra, S. R. R. Senthil Kumar, K. Chinnaraju, and F. Alfin Ashmita, "A comparative study on the compressive strength prediction models for High Performance Concrete containing nano silica and copper slag using regression analysis and Artificial Neural Networks," Construction and Building Materials, vol. 114, pp. 528-535, 2016.

[21] J. S. Chou, C. K. Chiu, M. Farfoura, and I. Al-Taharwa, "Optimizing the prediction accuracy of concrete compressive strength based on a comparison of data-mining techniques," Journal of Computing in Civil Engineering, vol. 9, no. 3, pp. 242-253, 2011.

[22] B. A. Omran, Q. Chen, and R. Jin, "Comparison of data mining techniques for predicting compressive strength of environmentally friendly concrete," Journal of Computing in Civil Engineering, vol. 30, no. 6, Article ID 04016029, 2016.

[23] H.-V. T. Mai, T.-A. Nguyen, Ly Hai-Bang, and V. Q. Tran, "Prediction compressive strength of concrete containing GGBFS using random forest model," Advances in Civil Engineering, vol. 2021, p. 12, Article ID 6671448, 2021.

[24] P. Chopra, R. K. Sharma, M. Kumar, and T. Chopra, "Comparison of machine learning techniques for the prediction of compressive strength of concrete," Advances in Civil Engineering, vol. 2018, pp. 1-9, 2021. 
[25] Code for Mix Design of Hydraulic concrete; DL/T5330-2005, Development and Reform Commission of the People's Republic of China, Beijing, China, 2005.

[26] M. Nili, M. Tadayon, and M. Nili, "The relationship between setting time and early age strength of concrete containing silica fume, fly ash and slag," in Proceedings of the Third International Conference on Sustainable Construction Materials and Technologies, pp. 18-21, the University of Kyoto, Kyoto Research Park, Kyoto, Japan, August 2013.

[27] S. M. Zhao and J. X. Gong, "Experimental study on the strength and shrinkage of high performance concrete with dual mineral admixtures," Concrete, vol. 02, pp. 81-86+89, 2016, (in Chinese).

[28] Specification for Mix Proportion Design of Ordinary concrete; JGJ 55-2011, Ministry of Housing and Urban-Rural Development of the People's Republic of China, Beijing, China, 2011.

[29] Test Code for Hydraulic concrete; SL352-2006, Ministry of Water Resources of the People's Republic of China, Beijing, China, 2006.

[30] P. Zhang, Q. Li, and H. Wei, "Investigation of flexural properties of cement-stabilized macadam reinforced with polypropylene fiber," Journal of Materials in Civil Engineering, vol. 22, no. 12, pp. 1282-1287, 2010.

[31] P. C. Aitcin, "The importance of the water-cement and water-binder ratios," in Science and Technology of Concrete Admixtures, pp. 3-13, Woodhead Publishing, Sawston, UK, 2016.

[32] J. W. Bullard, H. M. Jennings, R. A. Livingston et al., "Mechanisms of cement hydration," Cement and Concrete Research, vol. 41, pp. 1208-1223, 2011.

[33] D. Sari and A. G. Pasamehmetoglu, "The effects of gradation and admixture on the pumice lightweight aggregate concrete," Cement and Concrete Research, vol. 35, pp. 936-942, 2005.

[34] D. A. Abrams, Design of concrete Mixtures. Structural Materials Research Laboratory, Lewis Institute, Lewis Institute, Chicago, Illinois, 1919.

[35] Q. Y. Zhang, "Experimental study on concrete material performance of concrete face slab dam in high cold region," Master's Thesis, Zhengzhou University, Zhengzhou, China, 2016.

[36] C. C. Gong, J. Zhang, S. D. Wang, and L. C. Lu, "Effect of aggregate gradation with fuller distribution on properties of sulphoaluminate cement concrete," Journal of Wuhan University of Technology, vol. 30, pp. 1029-1035, 2015.

[37] H. Yan, J. Zhang, S. S. Rahman, N. Zhou, and Y. Suo, "Predicting permeability changes with injecting $\mathrm{CO} 2$ in coal seams during $\mathrm{CO} 2$ geological sequestration: a comparative study among six SVM-based hybrid models," The Science of the Total Environment, vol. 705, 2020.

[38] B. Dong, C. Cao, and S. E. Lee, "Applying support vector machines to predict building energy consumption in tropical region," Energy and Buildings, vol. 37, no. 5, pp. 545-553, 2005.

[39] T. Y. Liu, P. Zhang, J. Wang, and Yi-F. Ling, "Compressive strength prediction of PVA fiber- reinforced cementitious composites containing nano-SiO2 using BP neural network," Materials, vol. 13, p. 521, 2020.

[40] F. Niloufar, Y. Wei-Mon, M. T. Mohammad, and K. Alibakhsh, "The application of artificial neural networks to predict the performance of solar chimney filled with phase change materials," Design of concrete mixtures, vol. 171, pp. 1255-1262, 2018.
[41] Z. Z. Zhang, X. M. Ma, and Y. X. Yang, "Bounds on the number of hidden neurons in three-layer binary neural networks," Neural Networks, vol. 17, no. 7, pp. 995-1002, 2004.

[42] K. L. Zhou and Y. H. Kang, Neural Network Model and MATLAB Simulation Program Design, Tsinghua University Press, Beijing, China, (in Chinese), 2005.

[43] B. Huang and C. Ma, "A Shamanskii-like self-adaptive Levenberg-Marquardt method for nonlinear equations," Computers and Mathematics with Applications, vol. 77, no. 2, pp. 357-373, 2018.

[44] Code for Design of Highway Cement Concrete Pavement, Ministry of Communications of the People's Republic of China, Beijing, China, 2003.

[45] Q. F. Li and Q. Y. Zhang, "Experimental study on the compressive strength and shrinkage of concrete containing fly ash and ground granulated blast-furnace slag," Structural Concrete, vol. 20, pp. 1551-1560, 2019.

[46] S. Haruna, B. Mohammed, M. M. A. Wahab, and M. S. Liew, "Effect of paste aggregate ratio and curing methods on the performance of one-part alkali-activated concrete," Construction and Building Materials, vol. 261, Article ID 120024, 2020.

[47] C. B. Cheah, L. L. Tiong, E. P. Ng, and C. W. Oo, "The engineering performance of concrete containing high volume of ground granulated blast furnace slag and pulverized fly ash with polycarboxylate-based superplasticizer," Construction and Building Materials, vol. 202, pp. 909-921, 2019. 